\title{
Building WDM wide area resilient transport network from 4-node semi-mesh and mesh sub-networks
}

\author{
Limal, Emmanuel; Mikkelsen, Benny; Stubkjær, Kristian
}

Published in:

Communications, 1997. ICC 97 Montreal, 'Towards the Knowledge Millennium'. 1997 IEEE International Conference on

Link to article, DOI:

10.1109/ICC.1997.595002

Publication date:

1997

Document Version

Publisher's PDF, also known as Version of record

Link back to DTU Orbit

Citation (APA):

Limal, E., Mikkelsen, B., \& Stubkjær, K. (1997). Building WDM wide area resilient transport network from 4-node semi-mesh and mesh sub-networks. In Communications, 1997. ICC 97 Montreal, 'Towards the Knowledge Millennium'. 1997 IEEE International Conference on (Vol. 3). IEEE. https://doi.org/10.1109//CC.1997.595002

\section{General rights}

Copyright and moral rights for the publications made accessible in the public portal are retained by the authors and/or other copyright owners and it is a condition of accessing publications that users recognise and abide by the legal requirements associated with these rights.

- Users may download and print one copy of any publication from the public portal for the purpose of private study or research.

- You may not further distribute the material or use it for any profit-making activity or commercial gain

- You may freely distribute the URL identifying the publication in the public portal 


\title{
Building WDM wide area resilient transport network from 4-node semi-mesh and mesh sub-networks.
}

\author{
Emmanuel Limal, Benny Mikkelsen and Kristian E. Stubkjær. \\ Center for Broadband Telecommunications, Department of Electromagnetic Systems \\ Technical University of Denmark, Building 348, DK-2800 Lyngby, Denmark \\ Tel.: +45458814 44, Fax.: +4545931634
}

\begin{abstract}
This paper deals with optical transport network design using wavelength division multiplexing (WDM) facilities. It proposes a method for building networks from sub-network combinations. Two types of 4-node sub-networks and their properties are presented. For each sub-network, any fiber break can be recovered using re-routing paths. A European network set-up illustrates the method capabilities. The network has 19 nodes connected through 39 links distributed within 9 semi-mesh sub-networks. Comparison is made between local and non-local re-routing and between channel capacities of 2.5 and $10 \mathrm{~Gb} / \mathrm{s}$. The use of wavelength converters is also investigated. Advantages and drawbacks of different solutions are given with emphasis on fiber length and optical cross-connect size.
\end{abstract}

\section{Introduction}

Graphic solutions for designing physical topologies for wide area WDM networks have been widely investigated, e.g. [1][4]. The common way of designing networks is to minimize the total number of wavelengths required to route and re-route a given traffic. Generally, re-routing paths are established through sets of shortest paths. This requires a re-routing management within the whole network.

In this paper we design wide area networks (WAN) by combination of sub-networks, each satisfying criteria for fiber break recovery. This approach allows a local management of re-routing paths within a sub-network. Additionally, combinations of sub-networks to form larger network is considered feasible for practical evolution scenarios. Furthermore, in this paper, we minimize the kilometers of fibers and the sizes of optical cross-connects for a fixed and realistic number of wavelength-channels per fiber.

To illustrate the capabilities of the proposed method a European network is investigated. Several aspects are considered: resilience, signal quality and scalability [5]. Cost is also considered, in a simple way, through length of fiber and size of optical cross-connects (OXCs). Signal quality is maximized by minimizing the number of hops and the transmission distance. Easy scalability is ensured by the use of sub-networks.

We use the following notation: a link is a physical connection between two consecutive nodes and consists of a group of fibers, each containing a number of wavelength-channels. A wavelength-path [6] is a concatenation of wavelength-channels, each at the same wavelength. Similarly, a virtual-wavelengthpath is a concatenation of wavelength-channels, which can be at different wavelengths since wavelength converters can be employed at each node.

\section{Network design}

As mentioned above, we propose to construct networks from sub-networks. In this section we present the structures and properties of the semi-mesh and full-mesh sub-networks chosen as basic building blocks. To obtain the desired fiber break recovery, rules which allocate the occupied wavelengthchannels within a sub-network are also given. The advantages of sub-network combinations are then explained for understanding of network construction.

\section{Sub-networks}

\section{Sub-network structures}

Four-node sub-networks with node degree equal to or higher than two are considered. The node degree is defined as the number of links connected to a node. As shown in figure 1, there are 3 such sub-networks. The ring (a) will not be studied because it reaches optimum efficiency only when all links have the same load and therefore suffer from poor flexibility.

In the next paragraphs the semi-mesh (b) and the mesh (c) sub-

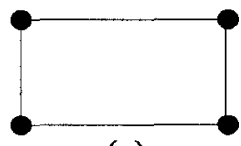

(a)

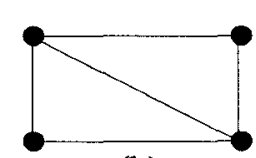

(b)

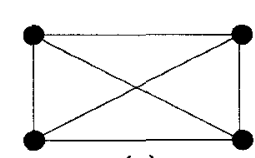

(c)
Figure 1: Possible 4-node sub-networks. Ring (a), semimesh (b) and full-mesh or mesh (c) structures. 
networks are investigated with and without optical wavelength converters (OWCs).

\section{Fiber break recovery}

The resilience of a network, i.e., the ability to survive a deficiency is of primary importance. Therefore, recovery of any fiber break has been taken into account in the sub-network design using re-routing paths. The re-routing strategy within the semi-mesh or the full-mesh sub-building blocks is depending on the use of wavelength converters. Figure 2 gives an example of a re-routing strategy in case of the semi-mesh sub-network with 4 wavelength-channels per fiber and without wavelength converters. The wavelength-channels $\lambda_{1}$ and $\lambda_{2}$ used to transport optical signals in the upper fiber (bold line) are rerouted through the dashed path if this upper fiber breaks.

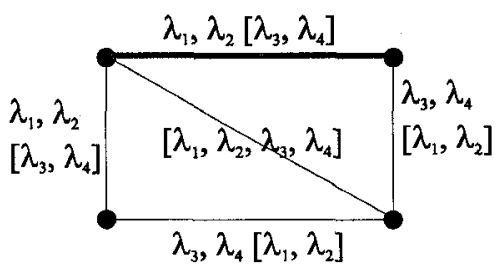

$\lambda_{1}, \lambda_{2}$ for routing

$\left[\lambda_{3}, \lambda_{4}\right]$ available in fiber $\left(\lambda_{1}, \lambda_{2}\right)$ for rerouting

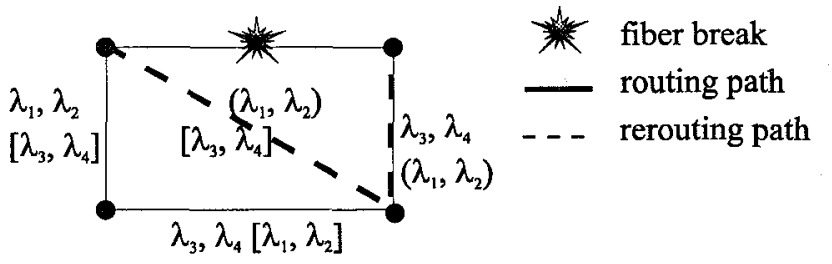

Figure 2: The wavelength-channels $\lambda 1$ and $\lambda 2$ used to transport optical signals in the upper fiber (bold line) are re-routed through the dashed path.

\section{Wavelength allocation in Semi-mesh sub-network}

The general rules that ensure the correct distributions of occupied wavelength-channels for full recovery of any fiber break are given in appendix A. Networks with and without wavelength-converters at the nodes are investigated. In this paragraph an overview of the rules is presented.

\section{Case 1: ' $m$ ' wavelength-channels per fiber. No wavelength} converters used.

The number of occupied wavelength-channels per fiber can vary from 0 to $\mathrm{m}$. For nodes with node degree two, only wavelength-channels with different wavelengths can be occupied within the two bi-directional fibers connected to the node. This is because if two wavelength-channels at the same wavelength are occupied, there is no available re-routing path for this wavelength. Similarly, for a node with degree three only two wavelength-channels at the same wavelength can be used. It can be easily verified that if three wavelength-channels of the same wavelength are occupied within the whole sub-network, there will be at least one of the fibers containing this wavelength which can not be recovered. Consequently, the total number of wavelength-channels possibly used in the subnetwork is twice the number of available wavelengths, i.e., ' $2 \mathrm{~m}$ '. Note that the total number of wavelength-channels in the sub-network is 5 times the number of available wavelengths, i.e., ' $5 \mathrm{~m}$ '. Therefore, $40 \%$ of the total capacity can be utilized.

\section{Case 2: 'm' wavelength-channels per fiber. Wavelength converters used.}

Nodes with degree two can have half of the wavelengthchannels occupied in the connected fibers without restriction on the wavelengths. Indeed the number of occupied wavelengthchannels in a fiber connected to a node must at most equal the sum of the free wavelength-channels of all other fibers connected to this node. Therefore in nodes with degree three, two thirds of the wavelength-channels within the connected fibers can be occupied, i.e., ' $2 \mathrm{~m}$ ' wavelength-channels. The number of wavelength-channels which can be used in the subnetwork is between ' $2 \mathrm{~m}$ ' to ' $3 \mathrm{~m}$ ', depending on the distribution of the occupied wavelength-channels. As an example, for ' $\mathrm{m}$ ' even, ' $3 \mathrm{~m}$ ' channels can be used if all fibers connected to nodes of degree two have ' $\mathrm{m} / 2$ ' channels occupied and, additionally, the diagonal is fully occupied (figure 3a). However, for a very unbalanced distribution of occupied channels, as given in figure $3 b$, only ' $2 \mathrm{~m}$ ' wavelength-channels can be used.

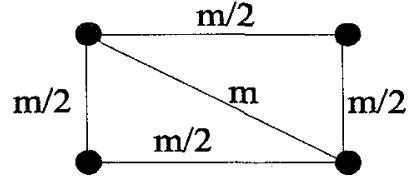

(a) ' $3 \mathrm{~m}$ ' channels used

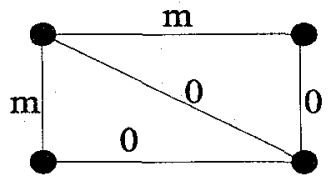

(b) ' $2 \mathrm{~m}$ ' channels used
Figure 3: ' $\mathrm{m}$ ' wavelength-channels per fiber. (a) illustrates the only case where the use of ' $3 \mathrm{~m}$ ' wavelengthchannels is permitted ( $m$ even). (b) is an example of a worst case channel distribution in terms of capacity.

Table 1 summarizes the features of semi-mesh sub-network with and without converters. The last row gives the relative gain in capacity obtained with OWCs compared to the case without OWCs. Ideally, the wavelength converters can give 50 $\%$ gain in capacity utilization. Part III of this paper will, however, illustrate that this is not achieved with a network loaded with an unbalanced traffic distribution. 
Table 1: Characteristics of the wavelength-channel distribution for optimum solutions with respect to channel utilization. Results are for four wavelength-channels per fiber.

\begin{tabular}{|l|c|c|}
\hline Semi-mesh & $\begin{array}{l}\text { with } \\
\text { wavelength } \\
\text { converters }\end{array}$ & $\begin{array}{l}\text { without } \\
\text { wavelength } \\
\text { converters }\end{array}$ \\
\hline total \# of $\lambda$-channels & \multicolumn{2}{|c|}{$20 \lambda$-channels } \\
\hline occupied $\lambda$-channels & $8-12$ & 8 \\
\hline $\begin{array}{l}\text { range of } \lambda \text {-channels } \\
\text { used }\end{array}$ & $40-60 \%$ & $40 \%$ \\
\hline $\begin{array}{l}\text { relative capacity gain } \\
\text { using converters }\end{array}$ & $0-50 \%$ & \\
\hline
\end{tabular}

\section{Wavelength allocation in Full-mesh sub-network}

The full-mesh structure is characterized by a node degree equal to three for all nodes. In this section, only the rules different from the semi-mesh cases are outlined. Details are given in appendix $\mathrm{B}$.

\section{Case 1: ' $m$ ' wavelength-channels per fiber. No wavelength converters used.}

In a full-mesh structure, three wavelength-channels at the same wavelength can be occupied. The total number of wavelengthchannels which can be used is ' $3 \mathrm{~m}$ ' out of the ' $6 \mathrm{~m}$ ' available, i.e., $50 \%$ of the total capacity.

Case 2: ' $m$ ' wavelength-channels per fiber. Wavelength converters used.

In this case, the number of wavelength-channels that can be used in the sub-network is between ' $3 \mathrm{~m}$ ' and ' $4 \mathrm{~m}$ ', depending on the occupied channel distribution. Several wavelengthchannel distributions exist that allow the use of ' $4 \mathrm{~m}$ ' channels; one of which is shown in figure $4 a$. For a very unbalanced distribution of occupied channels, as given in figure $4 \mathrm{~b}$, only ' $3 \mathrm{~m}$ ' wavelength-channels can be used.

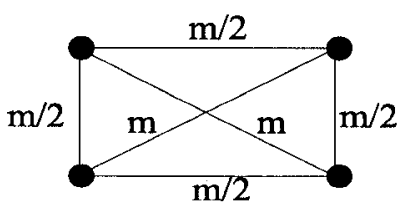

(a) ' $4 \mathrm{~m}$ ' channels used

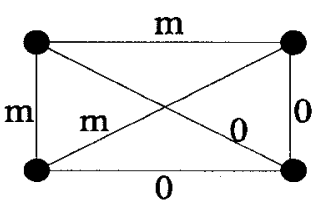

(b) ' $3 \mathrm{~m}$ ' channels used
Figure 4: ' $m$ ' WDM channels per fiber. (a) illustrates the only case where the use of ' $4 \mathrm{~m}$ ' wavelength-channels is permitted (m even). (b) is an example of a worst case channel distribution in terms of capacity.
Table 2 summarizes the results for the full-mesh structure through the example of 4 wavelength-channels per fiber. The relative gain offered by OWCs in terms of capacity is lower for the full-mesh structure than for the semi-mesh one. This confirms the general tendency that OWCs offer greater gain in capacity for "low-mesh" than for "high-mesh" architectures [7].

Table 2: Characteristics of the wavelength-channel distribution for optimum solutions with respect to channel utilization. Results for four channels per fiber.

\begin{tabular}{|l|c|c|}
\hline Semi-mesh & $\begin{array}{l}\text { with } \\
\text { wavelength } \\
\text { converters }\end{array}$ & $\begin{array}{l}\text { without } \\
\text { wavelength } \\
\text { converters }\end{array}$ \\
\hline total \# of $\lambda$-channels & \multicolumn{2}{|c|}{24 channels } \\
\hline occupied $\lambda$-channels & $12-16$ channels & 12 channels \\
\hline $\begin{array}{l}\text { range of } \lambda \text {-channels } \\
\text { used }\end{array}$ & $50-67 \%$ & $50 \%$ \\
\hline $\begin{array}{l}\text { relative capacity gain } \\
\text { using converters }\end{array}$ & $0-33 \%$ & \\
\hline
\end{tabular}

\section{Sub-network combinations}

This section presents two examples of sub-network combinations and their properties. Other combinations are possible, but those presented here are the ones used in the network shown in part III.

\section{Capacity gain from combination of sub-networks}

The two most attractive ways to combine sub-networks are the following: (a) two sub-networks are joined through one "common link" or (b) three sub-networks are connected by means of "common nodes" (figure 5).

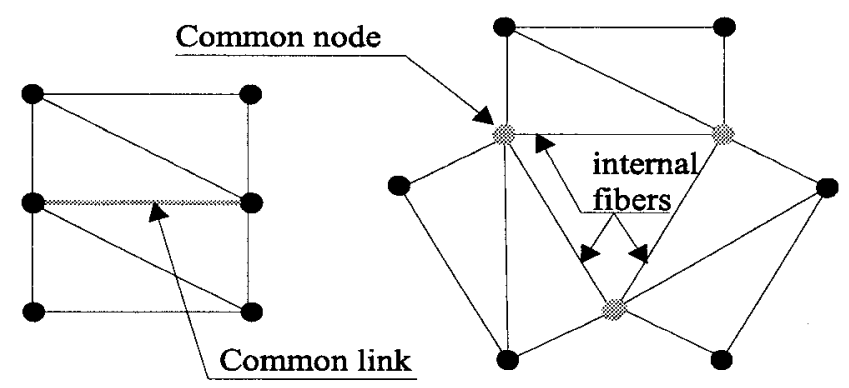

(a)

(b)

Figure 5: Two sub-networks connected by a 'common link' (gray line) (a) and three sub-networks are connected by means of three 'common nodes' (b).

In the following, we show that when two sub-networks (either semi-mesh or full-mesh) are combined, extra capacity is available. The rules for utilization of this extra capacity in the combined sub-networks are given below. 
Case 1: two sub-networks with no wavelength converters are connected by one unique fiber.

Due to the combination shown in figure 6 , each wavelength used in the "common fiber" ( $\lambda_{3}$ and $\lambda_{4}$ in the example) has two re-routing paths (one in each sub-network). Part of the extra rerouting path can be used to add extra capacity. As can be seen in figure 6 , an extra wavelength-channel at $\lambda_{3}$ can be used in one of the links with dashed line. Similarly an extra wavelength-channel at $\lambda_{4}$ can be used in one of the links with dotted line.

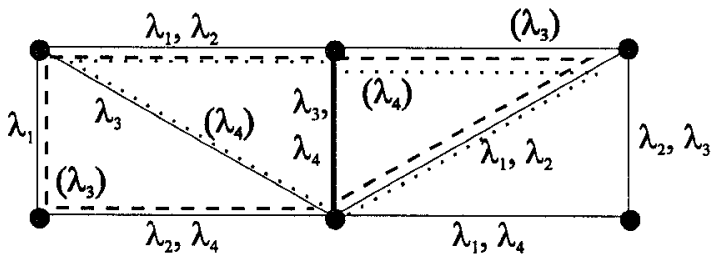

\footnotetext{
routing path for $\lambda_{3}$ and $\lambda_{4}$

$\lambda_{1}, \lambda_{2}$ used for routing

$\ldots$ rerouting path for $\lambda_{4}$

$\left(\lambda_{3}\right)$ used for rerouting

- rerouting path for $\lambda_{3}$
}

Figure 6: Two sub-networks are connected through one common fiber (bold line). The common fiber is possibly re-routed in both sub-networks.

After using all extra capacity available from the sub-network combination, all wavelength-channels have only one unique way to be re-routed. The network is then considered to be optimized with respect to the capacity utilization. Figure 7 shows the two sub-networks of figure 6 after utilizing the extra capacity. $\lambda_{3}$ and $\lambda_{4}$ of the common fiber have one unique rerouting path in figure 7 instead of the two paths from figure 6 .

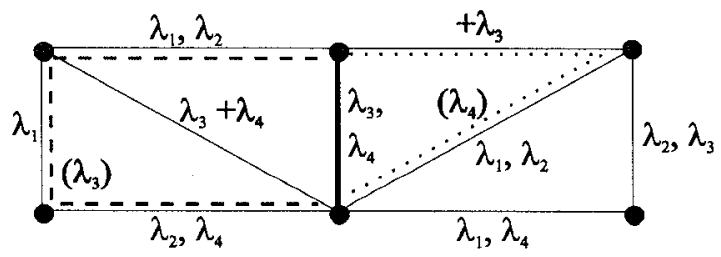

routing path for $\lambda_{3}$ and $\lambda_{4}$

$\ldots$ rerouting path for $\lambda_{4}$

- - rerouting path for $\lambda_{3}$

$\lambda_{1}, \lambda_{2}$ used for routing $+\lambda_{3}$ extra wavelengthchannel used

$\left(\lambda_{3}\right)$ used for rerouting

Figure 7: The common fiber can be rerouted only within the total network. All extra capacity has been used.

Case 2: three sub-networks with no wavelength converters are connected by means of 3 nodes.
As shown in figure 8 , each of the wavelengths, $\lambda_{1}$ to $\lambda_{4}$, can be re-used within one of the wavelength-channels of the three internal fibers. The gain in capacity is therefore equal to the number of wavelengths available.

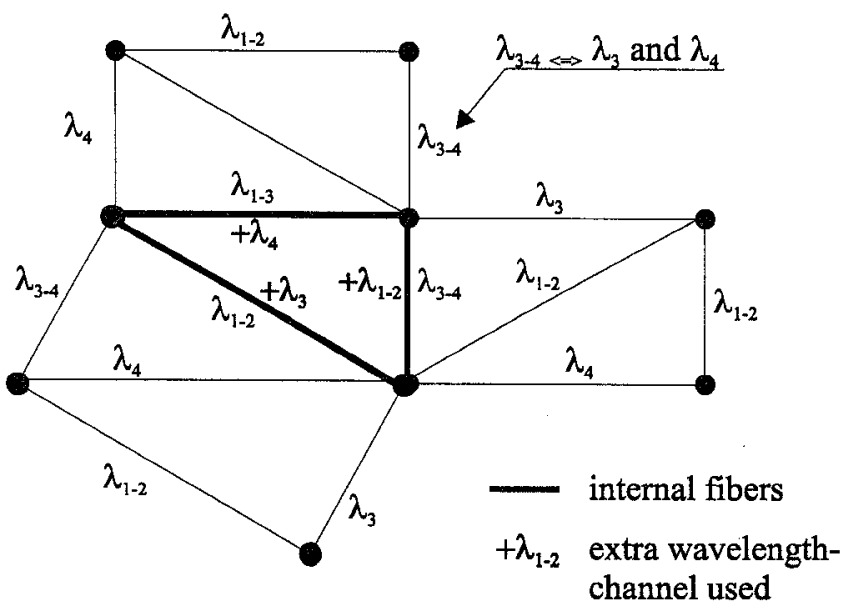

Figure 8: Three sub-networks with 4 WDM fibers connected together. Extra wavelength-channels (with wavelength $\lambda_{1}$ to $\lambda_{4}$ ) are added on the ensemble of the three internal fibers.

When sub-networks with converters are combined, rules are slightly different. Because of the higher relative occupation of the channels, combinations of sub-networks with converters give rise to a lower gain in extra capacity.

It should be emphasized, that the use of the extra capacity available from combining sub-networks always has as a consequence that all wavelength-channels cannot be re-routed within the same sub-network. In this paper we therefore use the term "global re-routing strategy (GRS)" for the strategy where all extra capacity available due to sub-network combinations is used. Similarly the term "local re-routing strategy (LRS)" denotes the strategy which allows any fiber to be recovered within a sub-network.

\section{European network}

In the following paragraphs, we will use the method described in section I to design a European network. The network has 19 nodes, located at the capitals of 19 European countries and is studied as part of the work in the OPEN ${ }^{1}$ project, that belongs to the European research program ACTS.

The traffic matrix is derived on basis of the work within COST-239 [1]: the traffic between two capitals is given by the product of the population of their respective countries divided by the distance between the cities and multiplied by a scaling factor [4]. If the traffic demand between two nodes is lower than $20 \%$ of $2.5 \mathrm{~Gb} / \mathrm{s}$ it is set to zero.

${ }^{1}$ Optical Pan-European Network consortium 
Using the derived traffic matrix and the design tools proposed in this paper, the network characteristics and the distribution of the sub-networks are presented.

\section{Network layout}

In the design of the network, small numbers of hops per (virtual-)wavelength-path and short (virtual-)wavelength-path distances have been attempted. Therefore, taking into account the unbalanced network load, the node degree is varying from 2 to 7 in the designed network. For example, a city in central Europe will have more traffic passing through it and thus higher node degree than cities located on the edges of the network. Figure 9 shows the resulting network.

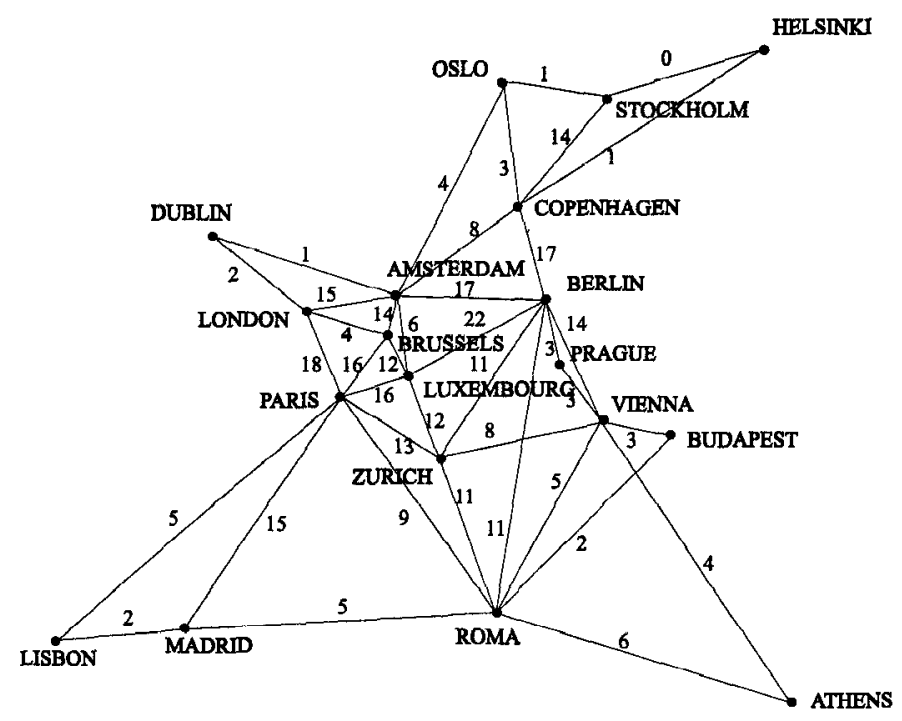

Figure 9: European network studied. Numbers indicates the total required capacity per link in $2.5 \mathrm{~Gb} / \mathrm{s}$ units.

The minimum number of links necessary for 19 nodes to be connected by semi-mesh sub-networks is 35 (7 sub-networks). To ensure a low average number of hops, several sub-networks are combined with common links. Therefore the number of links is increased to 39 distributed within 9 sub-networks.

In this network all wavelength-paths are routed through the path with the lowest number of hops, and if more than one such path exist, the path with the shortest distance is chosen.

\section{Layer of sub-networks}

The accommodation of a given link capacity can be done either in the wavelength or space (fiber) domain. We have chosen to use 4 wavelengths per fiber and a capacity per wavelengthchannel of 2.5 or $10 \mathrm{~Gb} / \mathrm{s}$, but other scenarios with 8 and 16 wavelengths per fiber are investigated. A significant difference between this work and the general presentation on network design [8] is that the rcsults on capacity optimization presented here are not given by a number of wavelengths needed, but by kilometers of bi-directional fibers and by the size of the optical cross-connects.

When a sub-network cannot handle the demand within at least one of its fibers, another sub-network is added on the top of the previous one (figure 10). This is repeated until all traffic can be routed within all links. The occupied wavelength-channels of each fiber within a link can be different. By definition, each sub-network is said to be in a layer. Local re-routing always occur within a unique layer. Importantly, to minimize the number of layers, wavelength-paths and virtual-wavelengthpaths can be switched from layer to layer at each node.

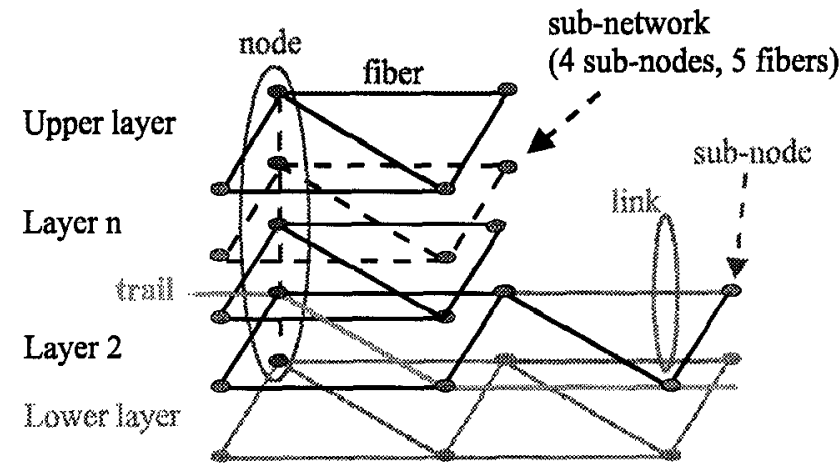

Figure 10: Illustration of the concept of superposition of sub-networks. The lower layer represents the physical topology. Other layers are added on a sub-network basis so that the traffic can be accommodated. The number of superimposed sub-networks varies.

\section{Evaluation of the network}

The criteria that are used to evaluate the network properties are given in table 3 . The table describes the physical properties of the network and its wavelength-path characteristics due to the traffic. By "add/drop wavelength-paths" we mean the number of wavelength-paths that is added/dropped into/from the network at an OXC.

The maximum link distance $(1452 \mathrm{~km})$ is not a limiting factor as transmission of $4 \mathrm{WDM}$ optical signals at $10 \mathrm{~Gb} / \mathrm{s}$ has been demonstrated over $1500 \mathrm{~km}$ of fiber [9]. With a low average number of hops of 1.65 per wavelength-path the wavelengthpath allocating problem is simplified.

Figure 11 shows the sub-network distribution in the network. The only requirement is that any link is included within at least one sub-network. 
Table 3: Physical properties and wavelength-path characteristics of the network.

\begin{tabular}{|c|c|c|c|}
\hline & Average & Min & Max. \\
\hline \hline number of node & 19 & - & - \\
\hline node degree & 4.1 & 2 & 7 \\
\hline number of link & 39 & - & - \\
\hline sum link length [km] & 23811 & - & - \\
\hline link length [km] & 610 & 173 & 1452 \\
\hline $\begin{array}{c}\text { wavelength-path length } \\
{[\mathrm{km}]}\end{array}$ & 918 & 173 & 2632 \\
\hline $\begin{array}{c}\text { number of hops per } \\
\text { wavelength-path }\end{array}$ & 1.65 & 1 & 5 \\
\hline $\begin{array}{c}\text { capacity per link for } \\
2.5 \mathrm{~Gb} / \mathrm{s} \text { per channel }\end{array}$ & $8.5 * 2.5 \mathrm{~Gb} / \mathrm{s}$ & 0 & $22 * 2.5 \mathrm{~Gb} / \mathrm{s}$ \\
\hline $\begin{array}{c}\text { capacity per link for } \\
10 \mathrm{~Gb} / \mathrm{s} \text { per channel }\end{array}$ & $5.1 * 10 \mathrm{~Gb} / \mathrm{s}$ & 0 & $11 * 10 \mathrm{~Gb} / \mathrm{s}$ \\
\hline $\begin{array}{c}\text { add/drop wavelength- } \\
\text { paths per OXCs for } \\
2.5 \mathrm{~Gb} / \mathrm{s} \text { per channel }\end{array}$ & 21.3 & 1 & 75 \\
\hline $\begin{array}{c}\text { add/drop wavelength- } \\
\text { paths per OXCs for } \\
10 \mathrm{~Gb} / \mathrm{s} \text { per channel }\end{array}$ & 11.47 & 1 & 28 \\
\hline $\begin{array}{c}\text { no. of subnets involved } \\
\text { per wavelength-path }\end{array}$ & 2.4 & 1 & 6 \\
\hline
\end{tabular}

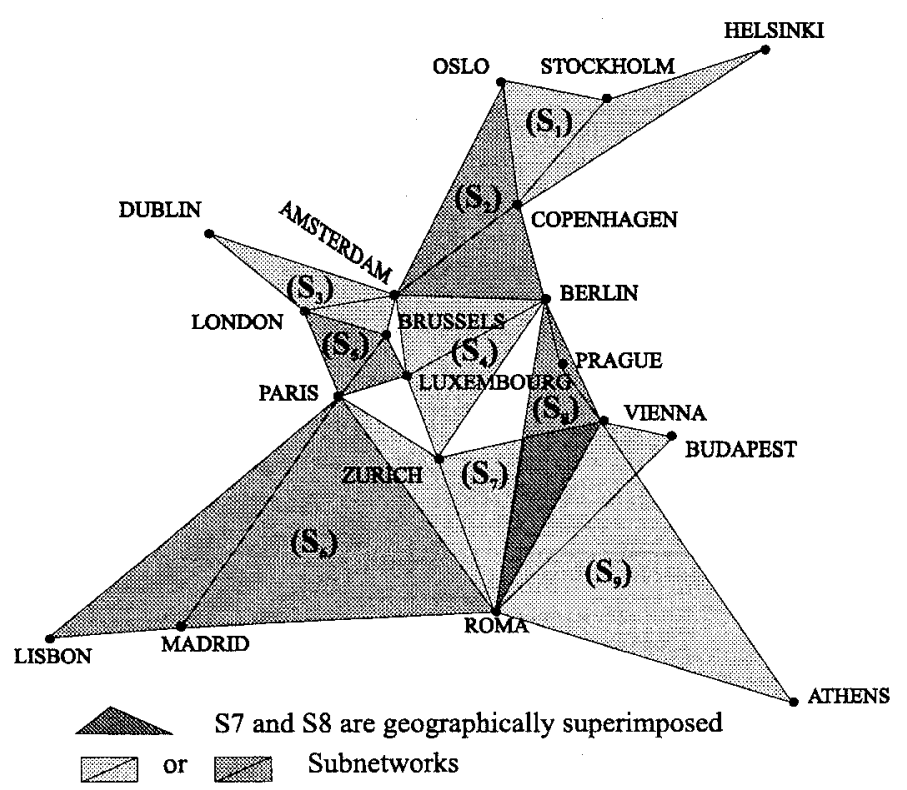

Figure 11: Sub-networks (all semi-mesh) are filled with different colors to be distinguished.

Finally, we would like to emphasize that the results from table 3 are valid in both cases with and without converters. This is because the function of the OWCs, in our approach, is to reduce the number of layers in each group of superimposed sub-networks rather than to reduce the number of wavelengths used which affect the routing paths.

\section{Results}

This third part is divided in three sub-paragraphs: (a) gives the outcome of the layer optimizations, (b) compares global and local re-routing strategy and (c) discusses the impact of wavelength converters at different bit rates.

\section{Outcome from the layer optimizations}

The optimization of the number of layers in each group of superimposed subnetworks affects the length of fiber used and the size of the optical cross-connects at each node. The optical cross connect considered here is based on a broadcast and select principle as proposed within the OPEN project [10]. It consists of a space switching stage, a filtering stage and a multiplexer stage. A wavelength converter stage can be added between the filtering and the multiplexer stages. The space switching stage consists of passive splitters, optical gates and combiners. In this paper the size of an OXC is evaluated in terms of the number of optical gates necessary in the switching stages. For $m$ wavelengths per fiber, $N$ input fibers and $M$ added/dropped wavelengths, the $\mathrm{OXC}$ size is estimated by:

$(\mathrm{N}+\mathrm{E}[\mathrm{M} / \mathrm{m}]) \mathrm{x}(\mathrm{Nxm}+\mathrm{M})$, where $\mathrm{E}[\mathrm{x}]$ is the ceiling function (it gives the closest integer larger than $\mathrm{x}$ ). The ceiling function represents the multiplexing of all the ' $M$ ' added wavelengths, into ' $E[M / m]$ ' fibers containing ' $m$ ' channels, before they enter the space switching stage.

The outcome of the optimization of the number of layers are given in table 4 . Both global and local re-routing strategies are investigated as well as the cases with and without OWCs. The results, that are given for granularity of 2.5 and $10 \mathrm{~Gb} / \mathrm{s}$, will be discussed in the following.

Table 4: Comparison of the kilometers of fiber and OXC sizes required in local and global re-routing in different cases. ${ }^{*}$ Average number of OWCs deployed at all output channels. ** The size of the OXCs is the average number of optical gates per node in the total network.

\begin{tabular}{|l|l|l|l|l|l|}
\hline $\begin{array}{l}\text { Re- } \\
\text { routing }\end{array}$ & $\begin{array}{l}\text { Capacity } \\
/ \text { channel }\end{array}$ & $\begin{array}{l}\text { conv- } \\
\text { erters }\end{array}$ & $\begin{array}{l}\text { Fiber } \\
\mathrm{km}\end{array}$ & $\begin{array}{l}\text { OWCs } \\
\text { per } \\
\text { OXC }\end{array}$ & $\begin{array}{l}\text { gates } \\
\text { per ** } \\
\text { OXC }\end{array}$ \\
\hline Global & $2.5 \mathrm{~Gb} / \mathrm{s}$ & no & 103367 & - & 3232 \\
\hline Local & $2.5 \mathrm{~Gb} / \mathrm{s}$ & no & 138712 & - & 5390 \\
\hline Global & $10 \mathrm{~Gb} / \mathrm{s}$ & no & 71926 & - & 1288 \\
\hline Local & $10 \mathrm{~Gb} / \mathrm{s}$ & no & 84190 & - & 1767 \\
\hline Global & $2.5 \mathrm{~Gb} / \mathrm{s}$ & yes & 103367 & 76 & 3232 \\
\hline Local & $2.5 \mathrm{~Gb} / \mathrm{s}$ & yes & 125548 & 92 & 4447 \\
\hline Global & $10 \mathrm{~Gb} / \mathrm{s}$ & yes & 71926 & 52 & 1288 \\
\hline Local & $10 \mathrm{~Gb} / \mathrm{s}$ & yes & 75031 & 54 & 1391 \\
\hline
\end{tabular}




\section{Global versus local re-routing}

As explained previously, the extra capacity resulting from combining subnetworks, decreases the required number of layers within the network. However, it implies the GRS.

The GRS compared to the LRS allows a gain in fiber length between 4 and $25 \%$ depending on the deployment of OWCs and the bit rate granularity. The highest gain in capacity is obtained for $2.5 \mathrm{~Gb} / \mathrm{s}$ without OWCs. Similarly, the gain in OXCs size is varying from 7 to $40 \%$ (highest at $2.5 \mathrm{~Gb} / \mathrm{s}$ without OWCs).

However the wavelength channel allocation for the GRS is much more complex than for the LRS. The GRS requires a central control for the whole network. Recovery of a fiber break would then obviously be more time consuming. With the LRS, the difference in number of hops between a routing wavelengthpath and its corresponding re-routing wavelength-path do not exceed 2. Furthermore, the LRS allows also several fiber breaks within the whole network. Moreover, local re-routing has the advantages that re-routing paths cross a minimum number of foreign countries.

In summary, the advantages of GRS in terms of fewer optical gates and less fiber spans are not considered to circumvent the disadvantages in terms of management complexity.

\section{Wavelength converters}

The use of OWCs do not significantly reduce neither the fiber length (from 138712 to $125548 \mathrm{~km}$ at $2.5 \mathrm{~Gb} / \mathrm{s}$ ) nor the average OXC size (from 5390 to 4447 optical gates at $2.5 \mathrm{~Gb} / \mathrm{s}$ ). This is in agreement with previously reported results [8][11][12] where OWCs reduce marginally the number of wavelength required to route a given traffic. The impact of OWCs is very small relative to the influence of the bit rate granularity. As an example, increasing the bit rate from 2.5 to $10 \mathrm{~Gb} / \mathrm{s}$ gives a reduction in fiber length of $40 \%$ with wavelength converters. Without the converters the corresponding number is $39 \%$.

The gain in fiber length and optical cross-connect size seems not to justify the deployment of OWCs. However wavelength converters simplify considerably the wavelength-path allocating problem by enabling assignments on a link by link basis. Moreover, by sorting the wavelength-paths before allocating them, the maximum number of wavelength conversions is reduced to a maximum of 2 per path. A fiber break would therefore not require more than 4 cascaded OWCs which has already been demonstrated at $10 \mathrm{~Gb} / \mathrm{s}$ [13]. Furthermore, OWCs also relax requirements to the absolute wavelength precision in the network [6].

\section{Conclusion}

A method for construction of optical WAN networks from 4node semi-mesh and mesh sub-networks has been presented. Each sub-network satisfies criteria to recover any fiber break using re-routing paths. Due to the combination of full survivable sub-networks, the resulting architecture of the WAN allows both local and global re-routing. An example of European network was then proposed as an illustration of the methods capabilities.

\section{References}

[1] M. J. O' Mahony et al., "The design of a European network" in Journal of.lightwave technology, vol 13. no. 5, May 1995.

[2] N. Wauters, P. Demeester, "Wavelength Requirements and Survivability in WDM Cross-connected Network" in ECOC '94. 20th European Conference on Optical Communication, 589-92 vol.2., sept. 1994.

[3] Hubert A.Jäger and Thilo Gipser, "Mapping of virtual Regular Mesh Network Topologies onto Arbitrary Geographical Node Distributions", in Technology, Infrastructure, WDM Networks, D.W Faulkner and A.L. Harmer (Eds), p. 64-71, IOS Press 1996.

[4] M. J. O' Mahony, 'Results from the COST 239 Project Ultra-high Capacity Optical Transmission Network" in proceedings of ECOC ' 96. 22nd European Conference on Optical Communication, TuB.1.2, sept. 1996.

[5] C.A. Brackett et al, "A scalable multiwavelength multihop optical network: a proposal for research on all-optical networks" in Journal of Lightwave Technology, p. 736-53 vol.11 no.5-6, May-June 1993.

[6] K. Sato, S. Okamoto and H. Hadana: "Network Performance and Integrity Enhancement with Optical Path Layer Technologies" in IEEE Journal on selected areas in communications, vol. 12, no. 1 , January 1994.

[7] M. Garnot et al., "Wavelength conversion in future WDM optical transport networks" in Digest IEEE/LEOS. 1996 Summer Topical Meetings, 47-48 TuB4., August 5-9 1996.

[8] Stefano Baroni and Polina Bayvel "Analysis of restoration in wavelength-Routed Optical networks" in Technology, Infrastructure, WDM Networks, D.W. Faulkner and A.L. Harmer (Eds), p. 56-63, IOS Press 1996.

[9] Hidenori Tage et al., "Four-Wavelength Multiplexed $10 \mathrm{~Gb} / \mathrm{s} \mathrm{IM-}$ DD Signal Transmission Experiments over $1500 \mathrm{~km}$ with $100 \mathrm{~km}$ EDFA spacing" in ECOC ' 94 . 20th European Conference on Optical Communication, 545-48 vol.2., sept. 1994.

[10] M.W. Chbat et al, "The OPEN (Optical Pan-European Network) ACTS Project: early achievements and perspectives" in proceedings of ECOC '96. 22nd European Conference on Optical Communication, WeP.11, sept. 1996.

[11] N. Wauters, P. Demeester, "Wavelength Routing Algorithms for Transparent Optical Networks" in ECOC '95. 21st European Conference on Optical Communication, 855-858, 1995.

[12] E. Karasan and E. Ayanoglu, "Effects of Wavelength Routing and Selection Algoritms on Wavelength Conversion Gain in WDM Optical Networks" in Digest IEEE/LEOS. 1996 Summer Topical Meetings, 43-44 TuB2., August 5-9 1996.

[13] B. Mikkelsen et al, "Transmission through 10 all-optical interferometric wavelength converters spans at $10 \mathrm{~Gb} / \mathrm{s}$ " in postdeadline papers OFC '96. Pd13.2-13.5, Part A, feb. 1996 


\section{Appendix A}

\section{Semi-mesh structure}

Theorem I and II present the rules (all referring to figure A) that manage the correct distributions of occupied wavelengthchannels. All signals transmitted through any fiber can be recovered in case of a fiber break. The use of wavelength converters is investigated. $\mathrm{m}_{\mathrm{ij}}$ is the number of occupied channels in fiber $F_{i j}$. If ' $p$ ' WDM channels are contained within a fiber, $m_{i j}$ can vary from 0 to $p$. The bit rate of the total signal transported by a fiber $F_{i j}$ is therefore the internal line rate times $\mathrm{m}_{\mathrm{ij}}$.

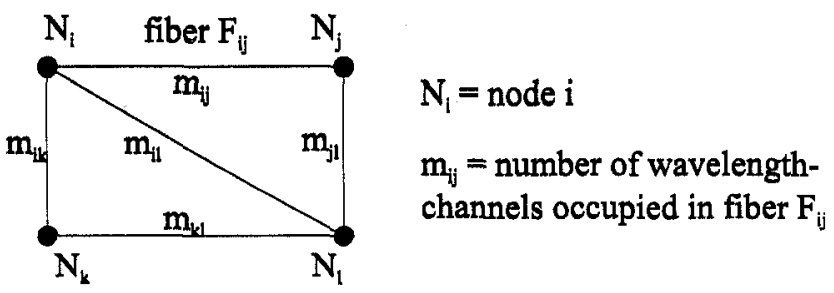

Figure A: Reference figure for theorem I and II.

\section{Theorem l:}

\section{Assumption I.1: without wavelength converters.}

Assumption I.2: ' $p$ ' wavelength-channels per fiber.

Legend: $\Sigma_{\mathrm{n}} \lambda_{\mathrm{n}}\left(\mathrm{N}_{\mathrm{x}}\right)$ is the sum of the wavelength-channels $\lambda_{\mathrm{n}}$ arriving in the node $\mathbf{N}_{\mathbf{x}}$.

(I.1) node $\mathrm{N}_{\mathrm{i}}: \quad \mathrm{m}_{\mathrm{ij}}+\mathrm{m}_{\mathrm{il}}+\mathrm{m}_{\mathrm{ik}} \leq 2 \mathrm{p}$

(I.2) node $\mathrm{N}_{\mathrm{l}}: \quad \mathrm{m}_{\mathrm{jl}}+\mathrm{m}_{\mathrm{il}}+\mathrm{m}_{\mathrm{kl}} \leq 2 \mathrm{p}$

(1.3) node $\mathrm{N}_{\mathrm{k}}: \mathrm{m}_{\mathrm{ik}}+\mathrm{m}_{\mathrm{kl}} \leq \mathrm{p}$

(I.4) node $\mathrm{N}_{\mathrm{j}}$ : $\mathrm{m}_{\mathrm{ij}}+\mathrm{m}_{\mathrm{jl}} \leq \mathrm{p}$

(I.5) all nodes: $m_{i j}+m_{i k}+m_{j l}+m_{i l}+m_{k l} \leq 2 p$

(I.6) nodes $\mathrm{N}_{\mathrm{i}}$ and $\mathrm{N}_{\mathrm{l}}: \quad \Sigma_{\mathrm{n}} \lambda_{\mathrm{n}}\left(\mathrm{N}_{\mathrm{x}}\right) \leq 2$, $\forall \mathrm{n} \in[1, \mathrm{p}] \cap \mathrm{N}, \forall \mathrm{x} \in[\mathrm{j}, \mathrm{k}]$

(I.7) nodes $\mathrm{N}_{\mathrm{j}}$ and $\mathrm{N}_{\mathrm{k}}: \quad \Sigma_{\mathrm{n}} \lambda_{\mathrm{n}}\left(\mathrm{N}_{\mathrm{x}}\right) \leq 1$, $\forall \mathrm{n} \in[1, \mathrm{p}] \cap \mathbf{N}, \forall \mathrm{x} \in[\mathrm{j}, \mathrm{k}]$

(I.8) all nodes: $\Sigma_{\mathrm{n}} \lambda_{\mathrm{n}} \leq 2, \forall \mathrm{n} \in[1, \mathrm{p}] \cap \mathrm{N}$

(I.9) all fibers: $\max \left(\mathrm{m}_{\mathrm{ij}}, \mathrm{m}_{\mathrm{ik}}, \mathrm{m}_{\mathrm{j}}, \mathrm{m}_{\mathrm{i}}, \mathrm{m}_{\mathrm{kl}}\right) \leq \mathrm{p}$

NB: (I.1) and (I.2) $\subseteq$ (I.5) and (I.6) $\subseteq$ (I.8)

Theorem II:

\section{Assumption II.1: with wavelength converters}

Assumption II.2: 'p' wavelength-channels per fiber.

(II.1) fiber $F_{i l}: m_{i l} \leq p-\max \left(m_{i j}, m_{j l}\right)+p-m a x\left(m_{i k}, m_{k l}\right)$

$$
\Rightarrow m_{i j}+m_{i k}+m_{j l}+m_{j l}+m_{k l} \leq 3 p
$$

(II.2) node $\mathrm{N}_{\mathrm{i}}: \mathrm{m}_{\mathrm{ij}}+\mathrm{m}_{\mathrm{il}}+\mathrm{m}_{\mathrm{ik}} \leq 2 \mathrm{p}$

(II.3) node $\mathrm{N}_{\mathrm{l}}: \mathrm{m}_{\mathrm{jl}}+\mathrm{m}_{\mathrm{il}}+\mathrm{m}_{\mathrm{kl}} \leq 2 \mathrm{p}$

(II.4) node $\mathrm{N}_{\mathrm{k}}: \mathrm{m}_{\mathrm{ik}}+\mathrm{m}_{\mathrm{kl}} \leq \mathrm{p}$

(II.5) node $N_{j}: m_{i j}+m_{j l} \leq p$

(II.6) all fibers: $\max \left(m_{i j}, m_{i k}, m_{j l}, m_{i j}, m_{k l}\right) \leq p$

\section{Appendix B}

\section{Full-mesh Structure}

Theorem III and IV give all rules to distribute the wavelengthchannels in a full-mesh structure. All rules refer to figure B.

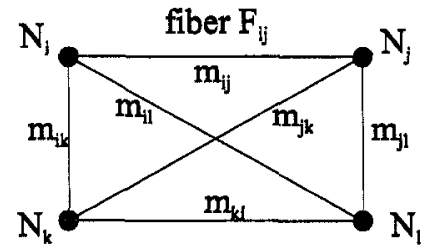

$\mathrm{N}_{\mathrm{i}}=$ node $\mathrm{i}$

$\mathrm{m}_{1 \mathrm{j}}=$ number of wavelengthchannels occupied in fiber $F_{i j}$
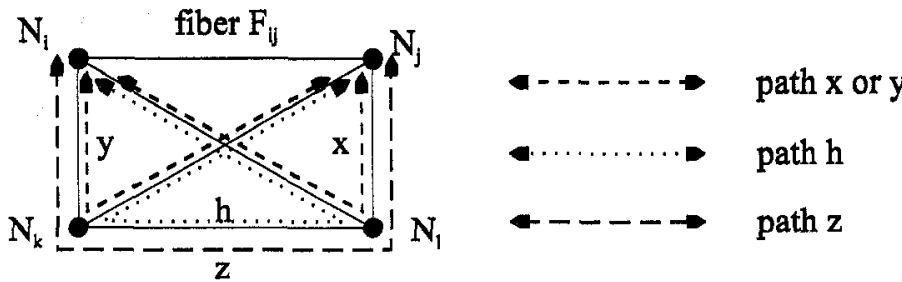

Figure B: Reference figure for theorem III and IV.

Theorem III:

Assumptions are those of theorem I.

(III.1) node $\mathrm{N}_{\mathrm{i}}$ :

(III.2) node $\mathrm{N}_{1}$ :

$\mathrm{m}_{\mathrm{ij}}+\mathrm{m}_{\mathrm{il}}+\mathrm{m}_{\mathrm{ik}} \leq 2 \mathrm{p}$

(III.3) node $\mathrm{N}_{\mathrm{k}}$ :

$m_{j l}+m_{i 1}+m_{k l} \leq 2 p$

(III.4) node $\mathrm{N}_{\mathrm{j}}$ :

$\mathrm{m}_{\mathrm{ik}}+\mathrm{m}_{\mathrm{kl}}+\mathrm{m}_{\mathrm{jk}} \leq 2 \mathrm{p}$

(III.5) all nodes: $\quad m_{\mathrm{ij}}+\mathrm{m}_{\mathrm{ik}}+\mathrm{m}_{\mathrm{jl}}+\mathrm{m}_{\mathrm{il}}+\mathrm{m}_{\mathrm{kl}}+\mathrm{m}_{\mathrm{jk}} \leq 3 \mathrm{p}$

(III.6) nodes $\mathrm{N}_{\mathrm{i}}, \mathrm{N}_{\mathrm{l}}, \mathrm{N}_{\mathrm{j}}$ and $\mathrm{N}_{\mathrm{k}}: \quad \Sigma_{\mathrm{n}} \lambda_{\mathrm{n}}\left(\mathrm{N}_{\mathrm{x}}\right) \leq 2$, $\forall \mathrm{n} \in[1, \mathrm{p}] \cap \mathrm{N}, \forall \mathrm{x} \in[\mathrm{i}, \mathrm{j}, \mathrm{k}, \mathrm{l}]$

(III.7) all nodes: $\quad \Sigma_{n} \lambda_{n} \leq 3, \forall n \in[1, p] \cap N$

(III.8) all fibers: $\quad \max \left(m_{\mathrm{ij}}, \mathrm{m}_{\mathrm{ik}}, \mathrm{m}_{\mathrm{jl}}, \mathrm{m}_{\mathrm{il}}, \mathrm{m}_{\mathrm{kl}}\right) \leq \mathrm{p}$

(III.9) for each fiber: $\quad x=\left(m_{i 1}+m_{j 1}-m_{k l}\right) / 2 \geq 0$

$\mathrm{y}=\left(\mathrm{m}_{\mathrm{ik}}+\mathrm{m}_{\mathrm{jk}}-\mathrm{m}_{\mathrm{k} l}\right) / 2 \geq 0$

$\mathrm{h}=\left(\mathrm{m}_{\mathrm{jk}}+\mathrm{m}_{\mathrm{kl}}-\mathrm{m}_{\mathrm{ik}}\right) / 2 \geq 0$

$\mathrm{z}=\left(\mathrm{m}_{\mathrm{jl}}+\mathrm{m}_{\mathrm{kl}}-\mathrm{m}_{\mathrm{il}}\right) / 2 \geq 0$

NB: (III.1-III.2) $\subseteq$ (III.6) and (III.5) $\subseteq$ (III.7)

\section{Theorem IV:}

Assumptions are those of theorem II.

$\begin{array}{ll}\text { (IV.1) node } \mathrm{N}_{\mathrm{i}}: & \mathrm{m}_{\mathrm{ij}}+\mathrm{m}_{\mathrm{il}}+\mathrm{m}_{\mathrm{ik}} \leq 2 \mathrm{p} \\ \text { (IV.2) node } \mathrm{N}_{\mathrm{l}}: & \mathrm{m}_{\mathrm{jl}}+\mathrm{m}_{\mathrm{il}}+\mathrm{m}_{\mathrm{kl}} \leq 2 \mathrm{p} \\ \text { (IV.3) node } \mathrm{N}_{\mathrm{k}}: & \mathrm{m}_{\mathrm{ik}}+\mathrm{m}_{\mathrm{kl}}+\mathrm{m}_{\mathrm{jk}} \leq 2 \mathrm{p} \\ \text { (IV.4) node } \mathrm{N}_{\mathrm{j}}: & \mathrm{m}_{\mathrm{ij}}+\mathrm{m}_{\mathrm{jl}}+\mathrm{m}_{\mathrm{jk}} \leq 2 \mathrm{p} \\ \text { (IV.5) all nodes: } & \mathrm{m}_{\mathrm{ij}}+\mathrm{m}_{\mathrm{ik}}+\mathrm{m}_{\mathrm{jl}}+\mathrm{m}_{\mathrm{il}}+\mathrm{m}_{\mathrm{kl}} \leq 4 \mathrm{p} \\ \text { (IV.6) all fibers: } & \max \left(\mathrm{m}_{\mathrm{ij}}, \mathrm{m}_{\mathrm{ik}}, \mathrm{m}_{\mathrm{jl}}, \mathrm{m}_{\mathrm{il}}, \mathrm{m}_{\mathrm{kl}}\right) \leq \mathrm{p} \\ \text { (IV.9) for each fiber: } \quad \mathrm{x}=\left(\mathrm{m}_{\mathrm{jl}}+\mathrm{m}_{\mathrm{jl}}-\mathrm{m}_{\mathrm{kl}}\right) / 2 \geq 0 \\ \qquad \begin{aligned} \mathrm{y} & =\left(\mathrm{m}_{\mathrm{ik}}+\mathrm{m}_{\mathrm{jk}}-\mathrm{m}_{\mathrm{kl}}\right) / 2 \geq 0 \\ & \mathrm{~h}=\left(\mathrm{m}_{\mathrm{jk}}+\mathrm{m}_{\mathrm{kl}}-\mathrm{m}_{\mathrm{ik}}\right) / 2 \geq 0 \\ \mathrm{z} & =\left(\mathrm{m}_{\mathrm{jl}}+\mathrm{m}_{\mathrm{kl}}-\mathrm{m}_{\mathrm{il}}\right) / 2 \geq 0\end{aligned}\end{array}$


Using the derived traffic matrix and the design tools proposed in this paper, the network characteristics and the distribution of the sub-networks are presented.

\section{Network layout}

In the design of the network, small numbers of hops per (virtual-)wavelength-path and short (virtual-)wavelength-path distances have been attempted. Therefore, taking into account the unbalanced network load, the node degree is varying from 2 to 7 in the designed network. For example, a city in central Europe will have more traffic passing through it and thus higher node degree than cities located on the edges of the network. Figure 9 shows the resulting network.

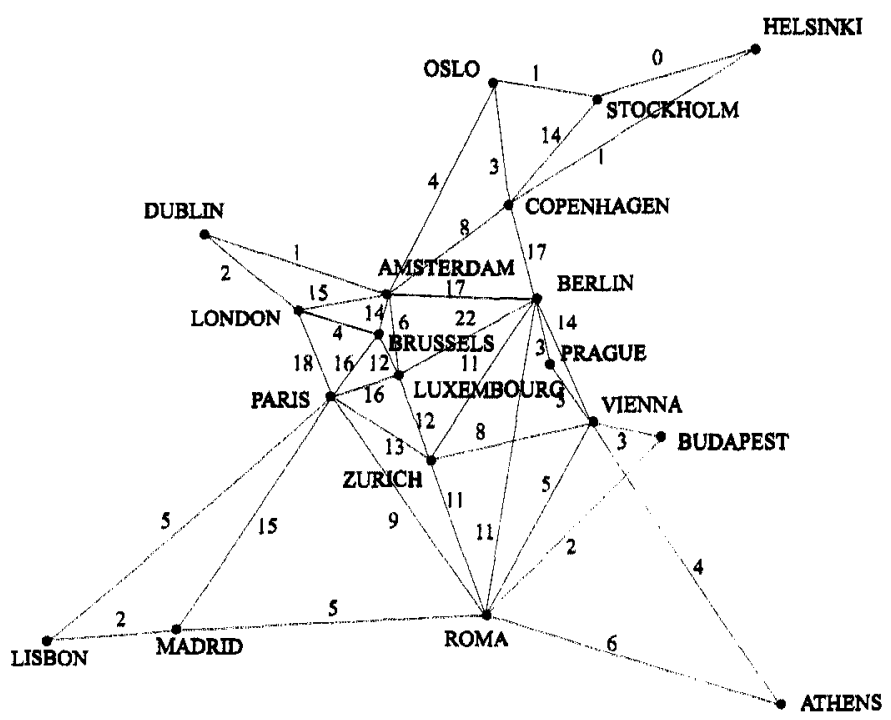

Figure 9: European network studied. Numbers indicates the total required capacity per link in $2.5 \mathrm{~Gb} / \mathrm{s}$ units.

The minimum number of links necessary for 19 nodes to be connected by semi-mesh sub-networks is 35 ( 7 sub-networks). To ensure a low average number of hops, several sub-networks are combined with common links. Therefore the number of links is increased to 39 distributed within 9 sub-networks.

In this network all wavelength-paths are routed through the path with the lowest number of hops, and if more than one such path exist, the path with the shortest distance is chosen.

\section{Layer of sub-networks}

The accommodation of a given link capacity can be done either in the wavelength or space (fiber) domain. We have chosen to use 4 wavelengths per fiber and a capacity per wavelength-channel of 2.5 or $10 \mathrm{~Gb} / \mathrm{s}$, but other scenarios with 8 and 16 wavelengths per fiber are investigated. A significant difference between this work and the general presentation on network design [8] is that the results on capacity optimization presented here are not given by a number of wavelengths needed, but by kilometers of bi-directional fibers and by the size of the optical cross-connects.

When a sub-network cannot handle the demand within at least one of its fibers, another sub-network is added on the top of the previous one (figure 10). This is repeated until all traffic can be routed within all links. The occupied wavelengthchannels of each fiber within a link can be different. By definition, each sub-network is said to be in a layer. Local rerouting always occur within a unique layer. Importantly, to minimize the number of layers, wavelength-paths and virtualwavelength-paths can be switched from layer to layer at each node.

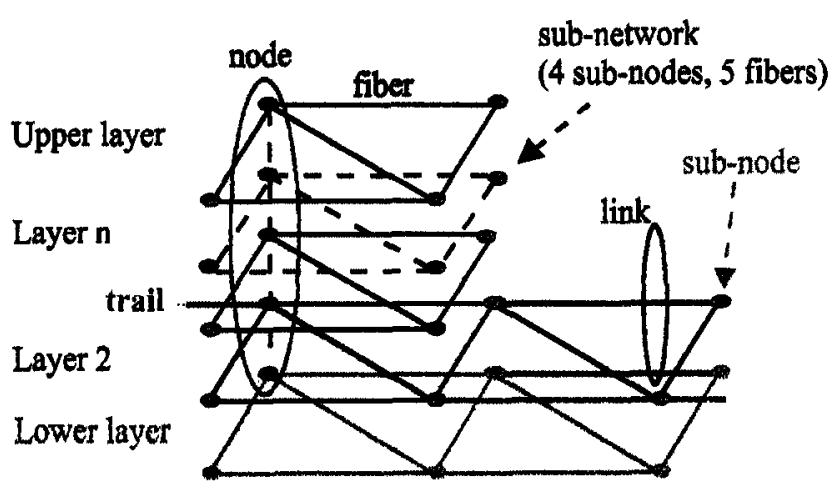

Figure 10: Illustration of the concept of superposition of sub-networks. The lower layer represents the physical topology. Other layers are added on a sub-network basis so that the traffic can be accommodated. The number of superimposed sub-networks varies.

\section{Evaluation of the network}

The criteria that are used to evaluate the network properties are given in table 3 . The table describes the physical properties of the network and its wavelength-path characteristics due to the traffic. By "add/drop wavelength-paths" we mean the number of wavelength-paths that is added/dropped into/from the network at an OXC.

The maximum link distance $(1452 \mathrm{~km})$ is not a limiting factor as transmission of $4 \mathrm{WDM}$ optical signals at $10 \mathrm{~Gb} / \mathrm{s}$ has been demonstrated over $1500 \mathrm{~km}$ of fiber [9]. With a low average number of hops of 1.65 per wavelength-path the wavelengthpath allocating problem is simplified.

Figure 11 shows the sub-network distribution in the network. The only requirement is that any link is included within at least one sub-network. 